\title{
A portaciones para una epistemología de los estudios sobre fronteras internacionales
}

\author{
Eusebio M edina García*
}

\begin{abstract}
Resumen. En este artículo proponemos un modelo interpretativo que puede servir como referente para abordar desde una perspectiva interdisciplinar los estudios sobre fronteras internacionales. Dicho modelo, inspirado en la teoría del campo social dinámico o campo sociocultural (Sztompka, 1995) y en los modelos de simulación social basados en inteligencia artificial (Lozares, 2004), se articula en cuatro dimensiones básicas: ideacional, normativa, materialista y agencial. El modelo es dinámico einteractivo y presuponela existencia de relaciones múltiples y complejas entre las cuatro dimensiones del campo, así como de una cierta autonomía en cada una de ellas. Dicho modelo está gobernado, además, por dos vectores fundamentales: espacio y tiempo. La dimensión espacial se refiere tanto al soporte físico y material, al territorio, como a otros aspectos, entre ellos la aprehensión psicológica del espacio y el espacio imaginario. En su dimensión histórica, temporal, consideramos que el modelo evoluciona constantemente sobre un fondo de mismidad suficiente para poder ser estudiado como hecho social. A bogamos aquí por la necesidad de construir una metodológica ecléctica que nos permita alcanzar una conjunción equilibrada entre los aspectos tangibles e intangibles, cuantitativos y cualitativos, macro y micro, interpretativos y comprensivos, singulares y compartidos, funcionales y crítico-racionales.

Palabras clave: fronteras internacionales, epistemología, modelo de simulación social, ciencia social aplicada.
\end{abstract}

\begin{abstract}
A bstract. In this paper, we propose an interpretative model to be used from an interdisciplinary perspective when undertaking international border studies. Inspired by the theory of social dynamic fields (Sztompka, 1995), this model is articulated in four basic dimensions: ideational, normative, materialist and agentive. The model is both dynamic and interactive; it presupposes the existence of multiple and complex relationships among the four field dimensions, as well as a certain degree of autonomy in each one. The model is also governed by two fundamental vectors: space and time. The spatial dimension refers to the physical and material base, as well as the territorial, and to other aspects such as the psychological apprehension of space and of imaginary space. It its temporal, or historical, dimension, we consider the model to be in constant evolution, on an oneness basis, to the extent that it can be studied as a social fact. We stress the need to construct an eclectic methodology in order to reach a balanced conjunction among various aspects: the tangible and intangible, quantitative and qualitative, interpretive and comprehensive singular and shared, functional and rational-critical.

Key words: international frontiers, epistemology, social simulation model, applied social cience.
\end{abstract}

* Universidad de Extremadura, España. Correo electrónico: emedina@unex.es 


\section{Introducción}

Actualmente disponemos de numerosos estudios sobre fronteras internacionales, acometidos desde una pluralidad de enfoques y perspectivas. La mayoría de tales abordajes se circunscribe a un espacio concreto, a una temática específica, y se construye con las herramientas y los procedimientos propios de una determinada disciplina: historia, geografía, sociología, antropología, etc. Esta absoluta preponderancia de los estudios especializados sobre las fronteras produce un efecto distorsionador, una pérdida de perspectiva sobre el conjunto, generando isl otes deconocimiento muy detallado en medio de un mar sin contornos. A nuestro parecer, la investigación especializada debe ir pareja con otros desarrollos teóricos y metodológicos que posi biliten la emergencia de una visión integrada sobre las fronteras internacionales. La nueva dinámica que generan los procesos de globalización en marcha, en su triple vertiente -flujos globales, individualismo radical e identidades de resistencia (Castells, M, 1998: 393 y ss.)-, requiere de nuevos conceptos y teorías que nos ayuden a interpretar esta compleja realidad.

Entre los entendidos se percibe la necesidad de acometer los estudiossobrefronteras desdeuna perspectiva interdisci plinar y transfronteriza que supere las limitaciones de los tradicionales enfoques historicistas y geopolíticos, los cuales se asientan, por lo general, en un concepto obsoleto de la frontera, ligado a los procesos de militarización, burocratización, centralización y legitimación de los estados nacionales. A unque existen numerosas aportaciones teóricas sobre la frontera, casi todas giran en torno al contenido del propio concepto (Lisón Tolosana, C., 1997: 141 y ss.) o derivan hacia sistemas clasificatorios meramente descriptivos (Foucher, M., 1997); por ello, no nos sirven para entender ni los procesos ni las dinámicas que se desarrollan en torno a las fronteras.

Las fronteras internacional es y sus espacios de interinfluencia constituyen marcos privilegiados para estudiar la mecánica y los efectos de numerosos fenómenos, relativamente nuevos, que se manifiestan en el presente, como el desdibujamiento de las fronteras nacionales, 
la deslocalización industrial, la emergencia de regiones transnacionales y sus nuevas fronteras subsecuentes, etc. Para entender tales fenómenos necesitamos desarrollar una epistemología de los estudios sobre fronteras que, sin frenar el avance colateral de los estudios especializados y de otras aproximaciones, nos permita obtener una visión general del fenómeno frontera. Necesitamos un marco de referencia que sirva como catalizador para los múltiples estudios y perspectivas, que posibilite a la vez un análisis de los procesos dinámicos y el establecimiento de tipologías y de comparaciones, tanto entre los segmentos espaciales de una misma frontera como de las diversas fronteras entre sí.

La comparación resulta esencial para entender el funcionamiento y la estructura del fenómeno, así como para captar las posibles regularidades detipo medio y general queen él semanifiestan. A pesar de sus limitaciones, la sistematización detal es regularidades posibilitará el establecimiento de modelos de funcionamiento que nos otorguen una cierta capacidad de predicción y, en consecuencia, de intervención intencionada para la reconducción parcial delosfenómenosy de sus probables efectos. Aunque pueda parecer utópico, dicha intervención debería estar impregnada devalores orientados al establecimiento deun nuevo orden internacional regido por el respeto delos derechos humanos, de la diversidad cultural, del medio ambiente... y abogar por la necesaria participación social y el reparto más equitativo de la riqueza en cualquiera de sus manifestaciones.

\section{Principios teóricos y metodológicos}

A continuación presentamos al gunos de los principios sobre los que debería asentarse, a nuestro parecer, una epistemología de los estudios sobre fronteras:

- Desarrollar una perspectiva interdisciplinaria, aprovechando las múltiples contribuciones específicas provenientes dela historia, la geografía, la ciencia política, la sociología, la economía, la antropología, la informática, etcétera. 
- Poner énfasis en lo transfronterizo, delimitando espacios de interacción eintercambios que comprendan ambos lados deuna misma frontera.

- Proyectar una visión dinámica e interactiva de la real idad, mostrando un especial interés por la descripción y la comprensión de los procesos en sus múltiples conexiones y consecuencias.

- Asumir la naturaleza ambigua y polival entede las fronteras y la validez de realizar sobre ellas múltiples aproximaciones.

- Admitir que el uso de modelos es reduccionista, pero también esencial para el desarrollo de tipologías y comparaciones que nos permitan identificar regularidades de tipo medio y general.

- Buscar la conjunción macro-micro, poniendo énfasis en las relaciones dialécticas y en las interacciones entreestructuras y agencias.

- Proyectar una visión emic-etic que posibilite la conjunción de métodosy experiencias, incluidas las experiencias del propio investigador.

- Utilizar diversos enfoques metodológicos y herramientas de investigación (triangulación).

- Defender una perspectiva crítica e intervencionista, abogando por el desarrollo de una ciencia social orientada al mejoramiento de la sociedad.

\section{Sobre la dimensión histórica}

A lo largo de la historia han variado considerablemente las concepciones en torno a las fronteras, así como su aprehensión y su intensidad. La progresiva sedentarización delas sociedades humanas marcó el inicio de un vasto proceso que culminó con la instauración generalizada delímites precisos, defronteras políticas y administrativas más o menos flexibles (Douglas Taylor, 1996; Mitre Fernández, 1997). Dicho proceso presenta nuevas singularidades que superan el ya tradicional concepto de frontera político-administrativa, perfectamente definida por un límite fijo sobre el territorio (Uriarte, 1994: 57 y ss.). Actualmente, las fronteras de los Estados-nación son rebasadas de múltiples maneras (Ruíz, 1996). El propio Estadonación ha permitido y propiciado el derrumbamiento desus fronteras 


\section{Modelo sociocultural para el estudio de las fronteras internacionales}

\section{Subcampo ideacional}

Imágenes de la frontera.

Principales elementos de las identidades socioculturales.

Representaciones simbólicas de las identidades socioculturales.

Fronteras étnicas, lingüísticas, religiosas, étnicas, simbólicas...

Cultura de frontera

\section{Subcampo normativo}

Valores y moralidad: normas y leyes.

Relaciones de poder: Estado y grupos de Estados.

Ejercicio del poder: mecanismos de legitimación.

Dispositivos del poder: policía y burocracia.

Fronteras políticas, fiscales y administrativas.

Orígenes de la frontera. Características del territorio. A prehensión psicológica del espacio.

Procesos de cambio social. Historia e intrahistoria.

\section{Subcampo materialista}

\section{Modelo económico.}

Relaciones de producción.

Intercambio y distribución de bienes.

Instituciones y organismos multinacionales.

Fronteras económicas y comerciales.

\section{Subcampo agencial}

Sujetos y experiencias.

Grupos, asociaciones y actores colectivos.

Intereses e interacciones.

Cultura de frontera y experiencia de vida.

Fronteras de la vida cotidiana.

Fuente: Elaboración propia. 
tradicionales y la emergencia de un nuevo paradigma, en el que la realidad fronteriza se vislumbra desde una perspectiva compleja, internacional y transfronteriza (Bustamante, 1996; Vanneph, 1997), inserta en diversos procesos de globalización (Castells, 1998), de reivindicación y reestructuración de las identidades colectivas (Zavala de Cosio, 1997; Valenzuela Arce, 1998; Velasco Ortíz, 2002).

Las dimensiones espacio-temporal presentes en las fronteras están estrechamente vinculadas entre sí. La frontera, al ser una creación histórica, aparece siempre inserta en un espacio-tiempo en constante mutación. La dimensión histórica del fenómeno frontera nos remite a su permanente provisionalidad, a su constante trasiego. Ésta nos incita a interesarnos por los procesos de transformación que acontecen en su seno. Como se ha dicho, los espacios de frontera constituyen entornos privilegiados para identificar tendencias y estudiar fenómenos emergentes, frutos en su mayor parte del acelerado proceso de mutación del mundo en que vivimos. La perspectiva histórica nos invita al abordaje de estos fenómenos en su dinamicidad, en su complejidad, formando parte de procesos indeterminados, en los que desempeñan un papel igualmenteimportante tanto la gran historia como la intrahistoria. Junto a la historia de la frontera recogida en los libros, cuya construcción, difusión y aprehensión han estado tradicionalmente sesgadas, la etnohistoria nos remite a las vidas de la gente fronteriza, apenas construidas y generalmente silenciadas. La conjunción de historia e intrahistoria, para su mutuo enriquecimiento, es un camino que aquí proponemos.

\section{Sobre la dimensión espacial}

Por espacio fronterizo se ha entendido bien al territorio exclusivo border- sobre el que ejerce su soberanía un poder o un Estado nación, o bien a una tierra de nadie que articula un espacio difuso, de transición -targ, frontier- entre culturas o civilizaciones colindantes; sin llegar apenas a comprender que las fronteras son, generalmente, ambas cosas a la vez. Incluso las fronteras más rígidas y mejor guardadas son cruzadas, una y otra vez, con un afán inaudito que a veces cuesta 
la vida. La presencia y la existencia física de la frontera, su levantamiento, posibilita e invita a la trasgresión, porque la frontera lleva implícito el tránsito en su misma naturaleza.

Como soporte físico, el territorio permite una amplia descripción y localización de infraestructuras productivas, recursos, denominaciones topográficas, espacios intermedios, densidades y flujos, etc. En este apartado deben incluirse, además de la descripción física del territorio fronterizo, los recursos materiales y culturales presentes en el espacio transfronterizo: riquezas del subsuelo, distribución de cultivos, ubicación de industrias, principales vías de comunicación, poblaciones, aduanas y pasos fronterizos, sitios arqueológicos, construcciones singulares, etcétera.

Sabemos que el espacio no es reductible al territorio (Ranfla González, 1984). Lo espacial también encuentra campos deexpansión en la imaginación y en la conciencia delos hombres. El lugar dondese vive se humaniza y nos humaniza. El territorio pasa a formar parte estructurante de la memoria individual y colectiva; es la tierra consagrada, la parte sentimental del territorio, un soporte para la vivencia y la representación simbólica sobre el que se asientan, se crean y se recrean los referentes de la identidad. Esta dimensión psicológica del espacio fronterizo resulta particularmenteinteresante para adentrarnos en los aspectos inmateriales del fenómeno, en ese rellano de identidad condensada, cargado emocionalmente, que raya con lo inconsciente. Las fronteras y las representaciones queaquí se construyen no coinciden necesariamentecon las fronteras territoriales, ya sea en sentido amplio -espacio fronterizo- o restringido -línea fronteriza-, aunque probablemente se da una cierta convergencia entre fronteras físicas y mentales. Es importante saber si predomina, y entre quiénes predomina, una visión unilateral o bien transfronteriza del espacio. Esto nos ayudará a establecer con mayor rigor los límites aproximados de cualquier espacio fronterizo teniendo en consideración las opiniones de los propios habitantes, aunque probablemente no lleguemos nunca a una del imi tación clara y precisa de los límites deestos espacios de frontera, puesto que su misma naturaleza se asienta en la indeterminación. 
Más allá del espacio organizado está el espacio imaginado, la terra incógnita, un mundo dondehabitan los monstruos y los mitos (Baudot, 1998). Aquí es donde se desarrollan las visiones fantásticas del mundo, las formas del caos, el ámbito de lo desconocido (Eliade, 1992). Es un mundo poblado por seres extraordinarios: cíclopes, ogros, hadas, dioses, amazonas...; seres que habitan en un espacio liminar de fronteras indefinidas y portentosos encuentros: el fabuloso Reino de Saba, la A tlántida, Ias SieteCiudades de Oro, las Minas del Rey Salomón, El Dorado, Cibola y Quiriva... Esta faceta imaginaria del espacio ha tenido un papel muy importante en la historia de los descubrimientos y las colonizaciones, arrastrando un impulso fundado en la codicia, en la imaginación, en el afán y la atracción por lo misterioso y desconocido. Fenicios, griegos, romanos, vikingos, portugueses, españoles y muchos otros han apostado sus fortunas y sus vidas contra una certeza imaginada. La progresiva reducción de los espacios inexplorados no ha supuesto la consecuente desaparición de esta importante dimensión espacial; por el contrario, ésta se ha trasladado a nuevos confines orientados al espacio infinito, el cual se va poblando, y ordenando, paulatinamente con nombres extraídos de los mitos.

\section{Subcampo ideacional}

En este nivel se concentra el imaginario colectivo, la visión que impera sobre los otros -semejantes y extraños, amigos y enemigos- y las barreras que nos separan de ellos -étnicas, lingüísticas, religiosas, históricas, simbólicas- (Lisón Tolosana, 1992). El nivel ideacional es, además, un campo donde florecen las representaciones colectivas ligadas a diversas ramas del arte: pintura, cine, música, literatura... La producción artística y la hermenéutica no sólo son necesarias, sino hasta imprescindibles para explorar estos espacios inaccesibles a la cuantificación. Es importante indagar en las imágenes que proyectan los artistas, especialmente los artistas que trabajan sobre lo fronterizo, porque actúan como catalizadores, como instrumentos de transmisión de conocimientos y sentimientos que están más allá de la mera comprensión. Este enlace empático, trascendental, se condensa y se soporta principalmente en imágenes y en símbolos. Su producción y reproducción se 
inserta en un proceso de remodelación constante, tanto de los contenidos como de los mecanismos, los sujetos, los soportes, y, en consecuencia, de la propia identidad. En dicho proceso, las relaciones de poder dadas en un momento histórico son determinantes pues ejercen su particular violencia simbólica (Bordieu y Passeron, 1977) y utilizan a la tradición, real o inventada (Hobsbawm y Ranger, 1985), como fuente de legitimación y como principal referente.

Consideramos que cualquier clasificación cerrada sobre los contenidos o los procesos en torno a la identidad fronteriza violenta y reifica la realidad, especialmente si nos referimos a sus aspectos intangibles, como son los relacionados con la cultura inmaterial. Ateniéndonos a dicha realidad, debemos poner de manifiesto la extraordinaria fluctuación de elementos y la complejidad de los procesos deinteracción que conforman una situación en un momento histórico determinado. Pretender construir una sola identidad cultural para toda una frontera parece, en principio, un despropósito, ya que seguramente existirán variaciones significativas de la identidad en uno u otro tramo, a uno y otro lado de una misma frontera. Es más, probablementela identidad fronteriza se teje, como en todas partes, mediante un juego de diferenciaciones y oposiciones, muchas de las cuales se dan con el vecino más inmediato que no siempre tiene por qué ser el del otro lado de la frontera.

Algunos autores defienden la existencia de una cultura de frontera en las franjas fronterizas. Dicha cultura estaría caracterizada por "una fluida permeabilidad sociocultural que estructura una fuerteinterdependenciasimétrica [asentada sobre] relaciones decomplementariedad einterdependencia" (Uriarte, 1994). A unque en la mayor parte de los espacios fronterizos existen evidentes manifestaciones que pueden avalar tal aseveración, consideramos queel concepto decultura defrontera debe incluir más que meras relaciones de complementariedad e interdependencia, simétrica o asi métrica; una cultura o subcultura de frontera debecontener una seriedeelementos distintivos, específicos, quela diferencien significativamente de las culturas matrices, y debe ser, además, percibida desde dentro y desde fuera desu ámbito territorial, en su especifidad, tanto por los sujetos queforman partede ella como por los demás (Barth, 1976). 


\section{Subcampo normativo}

En esteámbito sedesarrolla propiamentela frontera política, la frontera del poder, identificada en sus orígenes con la emergencia de los Estados nación europeos aunque, sin duda, estas fronteras rígidas tienen un origen muy anterior. Como ya hemos dicho, no conviene separar radicalmente a las fronteras políticas -border- de los espacios defrontera-frontier-, puesto que ambos van indefectiblemente unidos y tratarlos por separado violenta la natural eza misma del fenómeno.

En este subcampo se ubican los sistemas de representación institucionalizados, las organizaciones políticas, las normas y las leyes, los mecanismos y procedimientos para elaborarlas, aprobarlas, aplicarlas, etc. Aquí se manifiesta, pues, de manera aún más evidente, el ejercicio del poder. Interesa estudiar particularmente la estructura de representación y los procesos para tomar y ejecutar las decisiones; para ello tenemosqueindagar tanto en el papel delas organizacionesformales -partidos políticos, organizaciones profesionales, sindicatos- como informales -cárteles, mafias, grupos de presión-. Hay que evidenciar las conexiones entre estrategias políticas e intereses económicos del Estado y de los grupos de poder, su interinfluencia y los mecanismos de conexión-oposición-coordinación. Resulta igualmente importante describir el contexto político externo, especialmente el más inmediato, tomándolo como marco de referencia. Es preciso proyectar una visión histórica de las relaciones políticas transnacionales e internacionales de los Estados fronterizos, de las decisiones políticas que han tenido mayor repercusión sobre dichos espacios, de las tendencias, de los posibles escenarios de futuro, etcétera.

Las normas y las leyes reflejan, en general, la visión de lo político sobre la frontera, ejerciendo una influencia de carácter estructural, casi inmediata, sobre los demás niveles. Probablemente sea en este nivel normativo-legal donde se produce una correlación más directa entre acciones y consecuencias. Las relaciones políticas entre dos o más Estados, y particularmente las normas y disposiciones legales relativas a las fronteras, condicionan generalmente la evolución de los flujos de intercambio y el conjunto de las interacciones que se dan en los espacios de frontera, conformando incluso nuevas representaciones colec- 
tivas. El análisis del repertorio legal sobre las fronteras debe complementarse con el estudio de los procesos concretos para tomar decisiones y ejecutarlas, procurando identificar y medir, en la medida de lo posible, las variables explicativas que influyen sobre los resultados de dichos procesos.

\section{Subcampo materialista}

Ésta es probablementela dimensión más cuantificable de todas, a pesar de que presenta múltiples conexiones con los subcampos ideacional y agencial, quizá los menos operativos. Es la frontera de los intercambios económicos, ligada estrechamente con la frontera mercantil y burocrática, pero también con el juego de interacciones y representaciones simbólicas que se tejen y comparten entrela gente de la frontera.

El nivel delos intercambios material es transfronterizos está condicionado en gran parte por las leyes que regulan las transacciones comerciales transnacionales, las cuales se aplican mediante reglamentos técnicos y administrativos, mecanismos devigilancia y decontrol, registros y fiscalización de las operaciones, etc. Aquí encontramos las causas originales que han dado pie a muchas fronteras. La fiscalidad está presente en su origen y en su instauración. El establecimiento de una frontera-aduana constituye generalmente un fin en sí mismo, un afán por delimitar el territorio para controlar y fiscalizar los tránsitos en beneficio del poder instituido (Hinojosa Montalvo, 1998).

Siempre que sea factible, deberán cuantificarse las transacciones comerciales hacia uno $u$ otro lado, identificando al menos los principales productos, los puntos de origen y destino, las redes de distribución, la evolución de los intercambios, etc. Todo ello con base en las estadísticas oficiales contrastadas, si las hubiera, con los datos de uno y otro país. Asimismo, tenemos que reservar un apartado para la inclusión de actividades singulares, aquellas que tienen en la frontera la principal causa de su existencia, describiendo y descubriendo las razones de su presencia y persistencia. Otro aspecto importante a desarrollar serán las actividades económicas tradicionales de las personas que viven en la zona transfronteriza. Interesa obtener una 
visión desde dentro y desde abajo, inventariando y describiendo dichas actividades y ligándolas a los aspectos culturales de los intercambios; es decir, con aquello que parece actuar de manera independiente, y a veces incluso en contra, de un comportamiento meramente racionalista, basado en un simple cálculo del beneficio monetario.

En un espacio de frontera se dan, por lo general de manera conjunta, flujos de intercambio lícitos e ilícitos. El volumen relativo de dichos flujos apunta, en forma directa, a la naturaleza más o menos porosa deuna frontera cual quiera. La presencia deimportantes tráficos ilegal es de personas o mercancías denota una frontera rígida, una frontera de poder, en la que las relaciones institucionales transfronterizas están truncadas y son generalmente distantes, cuando no hostiles o de franco enfrentamiento. Interesa desarrollar, en este subcampo, el estudio de epifenómenos ligados a la frontera como los intercambios ilegales -contrabandos-, los flujos migratorios, etc. Respecto al contrabando, es preciso distinguir, al menos, entre contrabando de mercancías o de personas; establecer el ranking de los productos contrabandeados más importantesy, si es posible, el volumen aproximado y su evolución en el tiempo, los centros de origen y destino, los actores principales, las interacciones, las organizaciones, los puertos y los pasos, las redes del contrabando, etcétera (Medina, 2003).

\section{Subcampo agencial}

No podemos comprender la realidad de un espacio de frontera sin tener en consideración las actividades, las interacciones, las actitudes, las expectativas, las vivencias y las emociones de los sujetos que viven e interactúan en esos espacios liminares. Aquí estamos frente a la dimensión vivencial, personalizada y subjetiva de la frontera (Favet, 1997). Es una visión que se al oja en la conciencia de los sujetos, conformada con base en las experiencias comunes y singulares de cada uno. Interesan, pues, tanto las actividades circulares y recurrentes, como reflejos de estrategias dereproducción social compartidas, como las prácticas diferenciadas según las diversas posiciones sociales y los papeles desempeñados por los sujetos-actores. Este subcampo muestra además, a nuestro parecer, importantes interacciones con lo 
ideacional, a través de los procesos de producción y reproducción de las identidades propias y ajenas (Velasco Ortiz, 2004).

Debemos incidir en la aprehensión subjetiva del espacio fronterizo; el espacio simbólico sobre el que se levanta la propia identidad y el espacio emocional, en el que se posicionan los sentimientos y las vivencias; también en las interacciones e interrelaciones, en las relaciones de parentesco y en las afinidades. Interesa asimismo describir los grupos y las organizaciones presentes en la frontera, diferenciando entre organizaciones formales e informales, grupos primarios y secundarios, asociaciones, redes de ayuda, de intercambio, etc. Hay que estudiar con cierto detalle los efectos de los demás subcampos sobre las interacciones y la vida cotidiana en la frontera, así como las reacciones de la gente y las estrategias de adaptación ante tales cambios, sondeando la posible influencia de las agencias sobre las estructuras, de lo micro sobre lo macro y viceversa (Wright Mills, 1996; Giddens, 1993). El conocimiento y la ilustración acerca de cómo se vive la vida en un espacio de frontera, las oportunidades que brinda, los impedimentos que acarrea, los posibles y probables que dicha experiencia conlleva, los principales escenarios y los modos de interacción, las emociones que experimentan y manifiestan los sujetos, dan pieal desarrollo deuna etnosociología dela frontera, así como a otras aproximaciones singulares.

\section{O rientaciones para la operacionalización}

El fenómeno frontera sólo es parcialmente cuantificable. N umerosos aspectos y extensiones del mismo se desarrollan en espacios a los que no se puede tener acceso mediante $\mathrm{el}$ análisis cuantitativo, por completo que éstesea. Admitimos por tanto, desde el principio, las limitaciones de la cuantificación para dar cuenta de dichos aspectos esencialistas. Sin embargo, a pesar de su carácter reduccionista -y en cierta medida gracias a ello-, el model o permite la medición de numerosas variables ubicadas en todos los subcampos. Para la comparación de los índices estadísticos, una vez que éstos hayan sido convenientemente elaborados y validados, nos sigue pareciendo re comendable el método de descomposición conceptual propuesto por 
Lazarsfeld (1973). La estructura cuantitativa de cada frontera podría conformarse en torno a un índice general compuesto por varios subíndices referidos a cada subcampo y a las dimensiones espacial y temporal. Esto permitiría una clasificación tipológica de las fronteras en función del peso de cada subcampo y de las dimensiones espaciotemporal que las configuran, así como una contrastación sistemática entre ellas y entre partes, dimensiones o subcampos concretos de ellas. Los valores medios deberán establecerse por referencia a los valores medios obtenidos en una muestra representativa de fronteras internacionales; por ejemplo, para determinar la extensión de una frontera habrá que relacionarla con la extensión media de todas las demás, dicha media referencial servirá como valor de contraste para determinar si una frontera es más o menos extensa, intensa, antigua, porosa o urbanizada, siempre con relación a las demás.

Con el propósito de superar al gunas limitaciones inherentes a la perspectiva cuantitativa, aunque sin abandonar el ámbito de lo probabilístico, sería conveniente ordenar todo este cúmulo de informaciones en medios tecnológicos adecuados-inteligencia artificial-, de manera que pudiéramos obtener una visión contrastada, modular y sistemática de una situación dada en un espacio fronterizo determinado, en relación consigo mismo y con otros espacios. La aplicación de model os de simulación de fenómenos complejos, no lineales, mediante inteligencia artificial social, especial mente los sistemas expertos y los sistemas adaptativos complejos, nos permitiría profundizar en el conocimiento de los procesos y los mecanismos de interacción y cambio social, posi bilitándonos igualmenteestablecer escenarios probables desituación (Lozares, 2004), así como una determinada planificación estratégica.

Un modelo de simulación social no debe considerarse un producto rígido, acabado, sino siempre en construcción. Más que algo cerrado y definitivo debe ser una invitación al debate, a la intuición, una propuesta abierta a sugerencias y a posibles modificaciones que la mejoren y enriquezcan. La validez interna del model o se fundamenta en la ajustada correspondencia entre los sistemas de representación y la realidad del fenómeno que representan. Dicha validez se verá 
incrementada, paulatinamente, mediante una retroalimentación y un ajuste del modelo basados en la abducción (Lozares, 2004: 183 y ss.).

Las principales características del model o pueden ser las siguientes:

- En principio es un modelo abstracto, elaborado por el investigador.

- El modelo debe ser sencillo y abarcar todos los casos.

- El modelo se articula en cuatro subcampos de interacción: ideacional, normativo, material ista y agencial.

- Los subcampos aparecen interrelacionados, en sus diversos niveles, de manera compleja; pero también están dotados de una cierta autonomía.

- La variación en cualquiera de sus elementos produce una variación en algunos o en todos los demás.

- El modelo permite describir, explicar y realizar predicciones.

- El modelo es abierto y se va enriqueciendo con los resultados derivados desu aplicación práctica, la reflexión teórica, el análisis comparativo y la intuición.

- El model o es redimensionabley por ello facilita los análisis, tanto a nivel macro como micro, de entidades totales o de partes y subconjuntos.

- El model o constituyeen sí mismo una fuentefecunda dehipótesis y de reflexión teórica.

- El modelo sólo es parcialmente operacionable, convertible en algoritmos.

- La modelización del fenómeno se basará principalmente en reglas de lógica preposicional y en razonamientos basados en representaciones analógicas.

\section{A modo de conclusión}

A unque resulta cada vez menos congruente defender la validez teórica del concepto de frontera, asociado específicamente a la expansión del modelo de Estado nación europeo occidental, dichas fronteras existen y continúan marcando su impronta sobre el territorio, las 
vidas y las conciencias de la gente. En el mundo actual, y más aún en el que se avecina, se requieren nuevos conceptos y métodos de aproximación a la compleja realidad de las fronteras que nos permitan obtener un conocimiento contrastado y validado de su composición y de sus dinámicas de funcionamiento. A nuestro parecer, dicho conocimiento sólo se hará efectivo con el concurso de diversas disciplinas, comunicadas entre sí mediante marcos teóricos y metodológicos sólidos y compartidos que generen estructuras convergentes, sinergias, y posibiliten un tratamiento más amplio, imaginativo y sistemático de los datos.

No obstante, somos conscientes de que debido a la naturaleza esencial mente ambigua y polisémica del fenómeno frontera, su comprensión no puede reducirse a la identificación de conjuntos de relaciones significativas entre variables ni al establecimiento de modelos. Muchos de los componentes esenciales de las fronteras se desarrollan en el ámbito de las representaciones colectivas, pasando a formar parte constituyente -y determinante- de la conciencia y las acciones de la gente. La mayor parte de esos aspectos o componentes son y seguirán siendo intangibles, y por ello no parece adecuado su abordaje sólo empírico, el cual siempre será reduccionista; es por esto que requieren otro tipo deaproximaciones específicas y valiosas.

Por lo demás, no debe haber conclusiones en al go apenas iniciado. Lo que aquí planteamos ha de verse, pues, como una propuesta para la construcción de una epistemología de los estudios sobre fronteras internacionales. Creemos que una visión interdisciplinar y concertada puede arrojar mucha luz sobre las fronteras y los fenómenos singulares que se desarrollan con ellas, propiciando además la construcción de una ciencia social moderna, crítica y aplicada que sirva para mejorar las relaciones y las condiciones de vida de las personas en general.

\section{Bibliografía}

A vilés Muñoz, A. Mạ et al. (2001), A tlas de M exicali. U n espacio urbano en la estrategia internacional, Universidad Autónoma de Baja California, Mexicali. 
Baudot, G. (1998), “Fronteras políticas y fronteras imaginarias en la fundación de la América virreinal”, en D. Piñera Ramírez (comp.), Fronteras del beroamérica. N uevos enfoques históricos, Universidad Autónoma de Baja California, A sociación I beroamericana de Estudios sobre Fronteras, Universidad de Educación A bierta y a Distancia, México, pp. 25-41.

Bourdieu, P. y J. V. Passeron (1997), La reproducción: el ementos para una teoría del sistema de enseñanza, Laia, Barcelona.

Bustamante, J. A. (1996), “Etnicidad en la frontera. M éxico-Estados Unidos: una línea hecha de paradojas", en R. E. Ruiz y O. T. Ruiz, R eflexiones sobre la identidad de los pueblos, El Colegio de la Frontera Norte, Tijuana, pp. 36-55.

Castells, M. (1998), La era dela información. Economía, sociedad y cultura:

$\mathrm{V}$ ol 2. El poder de la identidad, Alianza, Madrid.

Douglas Taylor, L. (1996), “El desarrollo histórico del concepto de frontera", en M. Ceballos (coord.), D e historia e historiografía de la Frontera N orte, Universidad A utónoma de Tamaulipas, Instituto de Investigaciones Históricas, El Colegio de la Frontera N orte, Tijuana.

Eliade, M. (1992), El mito del eterno retorno, Emecé, Barcelona.

Favet, L. (1997), “La frontera y el Estado-nación en la perspectiva de los migrantes internacionales", en Las Fronteras del Istmo. Fronteras y sociedades entre el sur de M éxico y A mérica Central, Centro Francés deEstudios M exicanos y Centroamericanos, México, pp. 39-43.

Foucher, M. (1997), "Tipología de las fronteras contemporáneas", en Las Fronteras del Istmo. Fronteras y sociedades entre el sur de M éxico y A mérica Central, Centro Francés de Estudios Mexicanos y Centroamericanos, México, pp. 19-24.

Giddens, A . (1993), Sociología, Alianza, Madrid.

Hinojosa Montalvo, J. (1998), “El comercio en la península ibérica en los siglos bajo medievales", en A ctas de los II estudios de frontera. A ctividad y vida en la frontera, Diputación provincial deJaén, España, pp. 385-413.

Hobsbawm, E. y T. Ranger (1989), La invención de la tradición, EUMO, Barcelona. 
Lazarfeld, P. (1973), “De los conceptos a los índices empíricos”, en M etodología de las ciencias sociales, vol. I, Laia, Barcelona, pp. 35-46. Lisón Tolosana, C. (1997), Las máscaras de la identidad. Claves antropológicas, Ariel A ntropología, Barcelona.

(1992), Individuo, estructura y creatividad. Etopeyas desde la antropología cultural, A kal, Madrid.

Lozares, C. (2004), "La simulación social, ¿una nueva manera deinvestigar en ciencia social?", Rev. Papers, 72, Barcelona, pp. 165-188.

Medina, E. (2003), Contraban do en la Raya de Portugal, Institución Cultural El Brocense, Diputación provincial de Cáceres, España.

Mitre Fernández, E. (1997), “La cristiandad medieval y las formulaciones fronterizas", en Fronteras y fronterizos en la historia, Secretariado de Publicaciones e Intercambio Científico, Universidad de Valladolid, España, pp. 9-62.

Ranfla González, A . (1984), "Frontera política y espacio fronterizo", Revista Estudios Fronterizos, año II, vol. I, núms. 4-5, mayoagosto/ sept.-dic., IIS-UABC, Mexicali, pp. 47-68.

Ruiz, O. T. (1996), “El ir y venir: la relación transfronteriza”, en R. E. Ruiz y O. T. Ruiz, Reflexiones sobre la identidad de los pueblos, El Colegio de la Frontera N orte, Tijuana, pp. 56-64.

Sztompka, P. (1995), Sociología del cambio social, Alianza, Madrid.

Uriarte, L. Ma. (1994), La Codosera. Cultura de fronteras y fronteras culturales en la Raya luso-extremeña, Asamblea de Extremadura, Mérida, España.

Valenzuela Arce, J. M. (1998), El color delas sombras. Chicanos, identidad y racismo, El Colegio de la Frontera N orte, Tijuana.

Vanneph, A. (1997), "Frontera Norte: de las redes a la región transfronteriza", en Las Fronteras del Istmo. Fronteras y sociedades entre el sur de M éxico y A mérica Central, Centro Francés de Estudios Mexicanos y Centroamericanos, México, pp. 25-30.

Velasco Ortiz, L. (2002), El regreso de la comunidad: migración indígena y agentes étnicos. Los mixtecos en la frontera M éxico-Estados U nidos, El Colegio de la Frontera N orte, Tijuana. (2004), “M igración y fronteras: ser indígena más allá de la nación", en Rev. Aztlan. A journal of Chicago Studies, vol. 29, núm. 1, pp. 135-143. 
Wright Mills, G. (1996), La imaginación sociológica, Fondo de Cultura Económica, Madrid.

Zavala de Cosio, Mạ. E. (1997), “La Frontera N orte de México, singularidad demográfica y factores de cambio", en Las Fronteras del Istmo. Fronteras y sociedades entre el sur de M éxico y A mérica Central, Centro Francés de Estudios M exicanos y Centroamericanos, México, pp. 31-38.

A rtículo recibido el 25 de octubre de 2005 Artículo aprobado el 20 de abril de 2006 